\title{
Innovated Per Adult Human UNIT Method (PAHUM) vs. Error Bound PC in Food Systems
}

\author{
Sümer Haşimoğlu ${ }^{1, a, *}$ \\ ${ }^{1}$ Retired Academician, Independent Researcher, Schwerin, Germany \\ *Corresponding author

A R T I C L I N F O A B S T R A C T \\ Research Article \\ In social \& economic science disciplines, the lack of strong theories is often reflected in the lack of \\ well-accepted common metrics defined by a UNIT. PAHU Method vs. PC is developed to \\ investigate the feasibility of developing well-grounded common metrics/unit to advance \\ behavioural, economic-social, food security \& science research, both in terms of advancing the \\ Received : 13/07/2021 \\ Accepted : 20/10/2021 \\ development of theory and increasing the utility of research for policy \& practice. In addition \\ aiming, to consider whether a set of criteria can be developed for understanding when the \\ measurement of a particular construct is ready to be standardized \& to explore how the research \\ community can foster a move toward standardization when it appears warranted. In this globalised \\ society, even imperial measures are defined with reference to the metric/unit standards. A radical \\ evaluation method change in global food systems is needed to meet the challenges. State of the art \\ Keywords: \\ Per Capita \\ Food \\ Method \\ Household \\ Family \\ of PAHU Method /Age and Gender Corrected Per Capita (PC ${ }^{\text {agc }}$ ) is to evaluate demographic \\ structure, consumer \& past and future food consumption potential of developed \& developing \\ countries, target populations, their food sufficiency \& also food security evaluations of family and \\ households. It involves systematic attempts to create awareness of 19.4 percentage UNIT error \\ inherent to PC \& pave the way to food - other goods consumption evaluations plus global impact \\ of hunger \& environmental issues until 2020-2050-era. PAHUM was applied \& evaluated EU28 \\ demographic structure \& food consumption issues for 1999/2010/2020. Now it focuses on research \\ with systems approach, contributing to the development of tomorrow's food systems for \\ family/household evaluations including $\mathrm{CO}_{2}$ emissions-biodiversity relations. A radical evaluation \\ method change in global/EU food systems is needed to meet the global challenges, including \\ family/household on UNIT basis. The principal is always to ask questions "Why", "What" and \\ "How" will naturally unfold and found the reality of PAHUM. Reality is reality...
}

\section{Introduction}

Author's thirty year research and findings indicate that there is a consistency problem on used UNIT and not only among nations and its institutions also at the international level that do not use the same definitions and that gives too much space for arbitrary decisions that will damage the comparability of the statistical data afterwards. Failure to recognize and address the problems inherent to Per Capita (PC - Does not consider age and gender) production consumption evaluations will also result in erroneous projections, misappropriations of resources and discontent among consumers.

The aim of the article on PAHUM vs. PC assessment SCAFFOLDING is to develop, test, validate in real conditions and disseminate a new holistic, consistent and valid research model constructed by integration of a set of innovative strategies, methods and tools developed to reduce/eliminate the error coming from PC evaluations.
Furthermore, the visual aspect of innovation-thinking frameworks of PAHUM vs. PC encourages an increased application of information and communications to convey the proposed value proposition clearly.

The purpose of this publication is to inform the research that underpins policy analysis, and the negotiations and/or prescriptions that follow, such that these enhance, rather than worsen, the food security status of target populations on PC especially the developing countries by considering age and gender issues in evaluations. A clearer understanding of the often-obscured effects of evaluations on error bound PC vs. PAHUM on food security is therefore vital if the drivers of further reform are to result in changes to the benefit of food insecure and vulnerable target populations (Households) in developing countries. PAHUM intended to be complementary to the existing literature that explores the linkages between different 
UNITS/ measurements in economic evaluations and household poverty to explore the food consumption implications for food security, economic, social, environment and other global economics and vital evaluations.

The research article contributes to understanding these relationships by:- critically reviewing what is known from the existing literature and other resources so as to facilitate better targeted country-level research and analysis of food consumption and food security developments; - presenting a conceptual framework for understanding how PAHUM / recalibration of $\mathrm{PC}\left(\mathrm{PC}^{\mathrm{agc}}\right)$ or reforms can impact upon national and household-level food security; - providing an operational framework for assessing the outcome of past policies, and predicting the consequences of future initiatives, on national and household food security; proposing an agenda for research.

PAHUM vs. PC focus is justified by explaining the multiple avenues by which agriculture can determine and enhance both national and household food security. While any error due to misjudgement made on PC that changes the balance between food production and consumption/demand for a good or service in an agriculture economy can affect levels of food security, agriculture related reform is especially relevant because: (i) agriculture is one of the central contributors to food security in most developing countries, both via its direct contribution to the availability of food, and indirectly as a key engine of agricultural economic development and hence improved access to food, and (ii) agriculture is one of the most heavily distorted sectors in many countries and has, as a result, received significant attention in recent rounds of food consumption evaluations of the households.

The article discusses types of present methodological approach and UNITS that have been used in analysing the impact of agriculture economic and the implementation of policy and requires institutional reforms especially for the developing countries. One of the other objectives of the article are first, to identify systemic differences across literature and degree of reform, and their impact on agricultural performance; and second, to highlight specific issues which might be analysed in further research and presents a framework for conceptualizing and clarifying the relationship between suggested UNIT correction criteria, the strength of the response of the agriculture sector to that correction and the resulting potential impact on food security. The way in which PAHUM the conditions affect incentives and opportunities within food systems, often to the detriment of the most vulnerable households, are explained. The reader may therefore obtain the key points from the overview, literature review and then refer to the PAHUM vs. PC detailed supporting concept and method development criteria and explanations. The main purpose of is to identify specific issues and debates, which have, as yet, received inadequate attention in food security research, and more notably, in international policy forum:

Conceptualizing/Measurements: Currently, we have been satisfied with trying to find the right answer with the wrong UNIT that is PC. We must be open to rethinking how accurately the current methods (Per Capita - PC and other approaches-Adult Equivalent-AE/Adult Male Equivalent-AME, Consumer Unit-CU, Conjoint Analysis$\mathrm{CA}$, equalized estimates, etc.) represent the true nature
(Gender differences; male/female) and the age (Young and old) structure of the target population's consumer/demand potential. We must also be open to exploring the possibilities of other methods such as innovated PAHUM that may provide us with more viable means of analyzing and predicting production/consumption-demand patterns including food, food sufficiency and food security evaluations. Academic research has not kept pace with new developments in this field, and interdisciplinary research is very much needed. International arena currently facing a demographic challenge and our objective is to turn this key issue into an opportunity to provide policy-making agencies with a means to accurately analyze and predict the real consumer and consumption potential of the developed and developing countries and also the target populations including family and households.

It is for sure quality national and international data are essential for understanding social dynamics that are often the foundation for scientific research and policy development (Hallström and Börjesson, 2013). Recent decades have given rise to growing interest in food consumption and its effects on the environment and health, leading to a greater demand for reliable organic and conventional food-consumption data on PC basis. Such PC statistics are used in research to assess present and nutrient intake and environmental impacts, but also to predict future trends. Data on organic and conventional food consumption are also used to develop guidelines, policy programs, and strategic interventions regarding health, climate change, agricultural land-use and household issues. Methodologies for producing consumption statistics on PC suffer from a number of limitations and uncertainties that affect the overall reliability of the data. Lack of harmonization of definitions and regulations concerning how data are obtained and presented further complicates the combination and comparison of data from different countries and regions (i.e., EU by EUROSTAT) and globally (i.e., by FAOSTAT, IFPRI), (Hasimoglu, 2014a, b and 2018; Hasimoglu and Aksakal, 2015). The purpose of below extended discussion is not to denigrate the methods, procedures and evaluations used by other scientists / researchers that they use in food production / consumption - demand and food security issues. A unifying structure is presented and a contemporary definition of science communication positioned within this framework of PAHUM vs. PC that the definition of working on UNIT basis provides an outcomes-type view of science communication and provides the foundations for further research.

The state of art of PAHU Method /Age and Gender Corrected Per Capita ( $\mathrm{PC}^{\mathrm{agc}}$ ) (HasimogluCopyright(C1989-USA) is to evaluate demographic structure, population/consumer and past, present and future food consumption potentials plus creating sustainable future economic-social-political, family/household, environmental evaluations of developed and developing countries on $\boldsymbol{U N I T}$ basis. It involves systematic attempts to create awareness of 19.4 percentage unit error inherent to PC - (PC does not consider age and gender differences), (Figure 1.) and pave the way to food - other goods consumption evaluations plus global impact of hunger issues (Food security) until 2030-2050 era. 
Critical Point; Description of the problem and prejudice concepts: Recent research and also the evaluations indicated that many authors call for agricultural production increases of minimum (PC) $60 \%$ $100 \%$ by 2050 , based on two recent food-demand projections summarized by (Tilman et al. 2011 and Alexandratos and Bruinsma 2012). These goals appear clear and compelling, but they exaggerate the scale of the production increase needed by 2030-2050-era because they misinterpret the underlying projections and ignore recent production gains (Hunter et. al. 2017), including 20202030 era. Moreover, the projections are often simplified into a goal of doubling yields, which serves as an urgent rallying cry for research, policy, and industry. Noteworthy, that these evaluations deviates the interpretations of the data when evaluations are made on error bound PC metric. Eliminating hunger is a global and a national imperative and the MDG [Millennium Development Goals; later on 1 January 2016, the 17 Sustainable Development Goals (SDGs) with 169 targets - \#2. zero Hunger of the 2030 Agenda for Sustainable Development - adopted by world leaders in September 2015 at an historic UN Summit officially came into force (UN, 2016) which is broader in scope than MDGs by addressing the root causes of poverty and the universal need for development that works for all people and agenda hopes to get us there by sooner than 2030 . Essential for success and priorities are investments for enhancing food supply in the developing especially the leastdeveloped countries of the world. Our quest and research will also require improved, reliable population, hunger and nutrition statistics and meaningful and reliable method, data with proven correct or corrected metrics (UNIT) for tracking progress toward the "zero hunger" goal of 2030 of the target population including families and households.

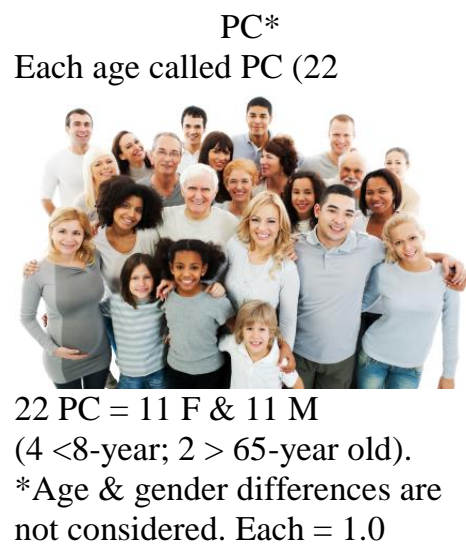

$\mathrm{F}(11)$ \& $\mathrm{M}$ (11) age groups

PAHU**

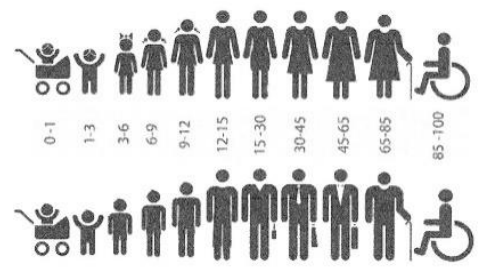

20-24-year old=PAHU $=1.0$

$\mathrm{PAHU}=$ Age $\&$ gender corrected Per Capita $\left(\mathrm{PC}^{\mathrm{agc}}\right)$.

Age groups $(11 \mathrm{~F} \& 11 \mathrm{M}): 0.1-4 ; 5-9 ; 10-14 ; 15-19 ; 20-24$ (PAHU)

25-34; 35-44; 45- 54; 55-64; 65-74; 75+.

PAHU or $\mathrm{PC}^{\text {agc }}=9.2$ female and 8.7 male $=17.9$ PAHU consumer not 22 .

Difference (Error) from PC is $22-17.9=4.1$ (20-24- year old) or 18.6

percentage unit from PC. (Table 1; Graphic 1.).

It shows itself in food/water consumption and $\mathrm{CO}_{2}$ emissions evaluations of target populations (Table 2., and Table 3.).

Figure 1. The PAHUM vs. PC concept, definition, conceptual framework and indicators

*NOTE 1: If we are measuring by using the wrong method (PC/GDP-PC) and/or measuring the wrong thing, we are going to do the wrong thing and end up with the wrong results leading to the wrong/distorted/distracted decisions making (Nobel Prize-winning economist, Joseph Stiglitz). ** NOTE 2. : BME is important for the human survival: Ten years after the development of the PAHUM, 1993 Economics Nobel Prize winner, Fogel (2000), stated that BMR is important for the human survival and After 30-year the development of the PAHUM vs. PC (copyrightC1989USA) three leading economists and academics at Davos agree - (IMF head Lagarde - now Head of EU Central Bank), Nobel Prize-winning economist Stiglitz, and MIT professor Brynjolfsson) in 2016 stressed that PC and GDP-PC is a poor way of assessing the health of our economies and we urgently need to find a new measure - UNIT.

***NOTE 3. : Standard PC and GDP PC statistics miss many of technology's benefits, so we need to rethink how we measure the typical person's well-being. "We need a new model for growth. Just as we're reinventing business, we need to reinvent the way we measure the economy," the MIT professor Brynjolfsson added (World Economic Forum, 2016; Thoma, 2016).

Background and Issues: Consumer demand and food systems are complex and offer many entry points for change. In addition, the data to describe food systems (Differing methods, measurements, metric (s) used in evaluations) their performance is scattered and not interoperable. Metric (s) that are used in evaluations are: PC; Adult Equivalent- AE/Adult Male Equivalent-AME, Conjoint Analysis - CA, in Household Consumption Evaluation (HCE) and suggested PAHUM vs. PC. In effect we all are trying blind in our evaluations of food security to change food systems for the better. Identifying cost and time-efficient approaches to food security and nutrition monitoring, metrics, methods and programs is essential to increasing the utility and sustainability in their applications, especially in developing countries. Novel research, innovative technology solutions, and silobreaking collaborations are changing the way we provoke change within each stage of our food systems and food security solution attempts (Hasimoglu, 2018). Food security is a multi-faceted concept, variously defined and interpreted. At one end of the spectrum food security implies the availability of adequate supplies at an international and national level; at the other end, the concern is with adequate nutrition and well-being of the households. Author is sure that the views/approaches of the scientific world will be changed after the global Corona Pandemic. Covis-19 also will effect and change the food consumption pattern, the habits and customs of the families, households, rural and urban consumers. 


\section{Materials and Methods}

Per Capita (PC) and Recalibrating PC Evaluations for Sustainable Intensification of the Food Security Considerations

We may have to get acquainted with of some terminologies and their definitions related to concept and developed method(s) - PAHUM:

1. Per Capita - PC: "by heads" or "for each head" or "for each person", i.e., per individual/person. Per capita simply means 'per person'. The term is commonly used in economics, statistics and human geography. The phrase is used with economic data or reporting but is also applied to almost any other occurrence of population description. Therefore, it can be a misleading number because it includes everyone from infants to senior citizens and fails to account for statistical outliers (Benton, 2020). PC provides a way to approximate how an organization affects each individual. It is removal of surroundings or its small structure of parts by denudation which is an erosive process. It can not be considered as UNIT. We have to ask "Is it a correct statement?" Per Capita - PC - metric as UNIT evaluations may imply conflict and we do it without thinking all the time. Comparing of averages, comparing to PC-metric as UNIT which is simplification may also misleading and their averages are no exception. Averages mislead by hiding a spread (a range of different numbers) in a single number. We risk misleading ourselves even more by focusing on the gap between those two single numbers and misleading the overlapping spread (i.e., Age groups and gender differences), the overlapping ranges of numbers that make up each average. We almost, always get a more accurate picture by digging a little deeper and looking not just the averages but at a defined UNIT (Hasimoglu, 1989, 2014a and b; 2018; 2020 and 2021).

2. Per Capita (PC) use and generalization instinct: Everyone automatically categorizes and generalizes all the time, for example PC = one person - (No description - Young, old, mature, male and female). As Rosling et. al. (2018) indicated "Misleading generalization and stereotypes act as a kind of shorthand for the media, providing quick and easy ways to communicate. When many people become aware of a problematic generalization it is called stereotype (Cliché). Most commonly $-\mathrm{PC}=$ (adult male or female) and also people talk about race, age and gender stereotyping. To control the generalization instinct, question your categories/target population (Rossling et al., 2018) and they summarized that; 1 . Look for differences within groups; 2. Look for similarities across groups; 3 . Look for differences across groups; 4. Beware of the majority; 5 . Beware of vivid examples and 6. Assume people are not idiots. In addition societies develop/developing move and change, non-western societies, cultures often move much faster. Notice the constant transformation... Lifespan in Africa is 65, in west 82, Tunisia, Algeria- it is 72 years. They are where Sweden was in 1970 . Economics 1993 Nobel Prize winner Fogel (2000) highlighted the similar observations. So, PAHUM opens the door for us to look into who consumes the most - men, women, elderly, young, children and babies? We are talking about the misconception and the gap between PC and innovated PAHUM and food security evaluations.

3. Population Dynamics: Population dynamics is the branch of life sciences that studies the size and age/gender composition of populations as dynamical systems and the biological and environmental processes driving them. It is for sure that population analysis matters because it is important (UNFPA, 2012): Population dynamics have a significant influence on sustainable development. Efforts to promote sustainable development that do not address population dynamics will continue to fail. Certainly it effects the food production consumption evaluations and also the future food security.

4. Metric and measurements on UNIT basis: It should be highlighted here that the units we agree on are all about accurate calculation and communication. Definition: A metric is a quantifiable measure that is used to track and assess the status of a specific process (Quora, 2020). This is why the term metric has a more goal or performance nuance attached to it. A measure is a number or a quantity that records a directly observable value or performance. "All measures are composed of a value (a number) and a unit of measure." The number provides magnitude for the measure (i.e., how much), while the unit gives number meaning (i.e., what is measured) (Carebot, 2020). In social science disciplines, the lack of strong theories is often reflected in the lack of well-accepted common metrics defined by a UNIT. In this globalised society, even imperial measures are defined with reference to the metric/unit standards.

5. A Serious Problem Requires a Serious Database: Knowledge or determination where the PC-error comes from some solutions are great for solving some/most problems but non of them will solve all problems. So PAHUM looks at it from different ways and perspectives. Predicted/found numbers have their limits unless supported by the data and proposed concept, method and used UNIT. In PAHUM vs. PC research, one needs to have the data to test its hypotheses, but hypotheses themselves often emerged from different observations though it requires numbers to understand the sociologic, economic, food security and other "Sustainable Development Goals" SDGs' consequences. Biology and its essential part nutrition for survival and its integral part energy is another area that is necessary for living things and human beings. Things that are not satisfied with just being, like rocks and dirt, but grow, change, live and die. This is what makes us living. To become a living thing, food, nutrition and energy/protein that it supplies for biological process is crucial. As biological creatures, we should grasp the very basics of what makes us tick. PAHUM or PC ${ }^{\mathrm{agc}}$ is defined as UNIT that converted the five-year interval age and gender groups into 20-24-year old $M / F$ that is selected as designated UNIT. Because biologically, physiologically and from nutritional stand point up to that age growth is completed and after that age, weight accumulation is always not protein but fat. It is for sure that problem can not be understood without numbers and without correctly selected metric/UNIT and methods.

\section{PAHUM vs. PC Method and Concept}

A. Biological Process, the Gap between Per Capita (PC) and Innovated Per Adult Human Unit Method (PAHUM) - Questions and answers, detailed more comprehensive literature review: (Method requires answering the "Why", the "What" and the "How" questions). Below author tries to explain the PAHUM concept and questions sequentially. 
The WHY Question: Importance of measurement on correct metric - UNIT basis. Metric/Unit - PAHU measures of nutritional outcomes

It is for sure that problem can not be understood without numbers and without correctly selected metric (s) and methods. All metrics have inherent strengths and limitations and those who use them in their work must ultimately acknowledge these trade-offs. Indeed, a common trade-off seen among food security metrics is comprehensibility and contextual detail exchanged for simplicity and comparability. This trade-off is clearly observed in the development of experience-based food security measures (Jones et al., 2013).

Last thirty years measurement issue discussed among researchers but this issue recently has received much attention and many indicators plus some metrics have been proposed and applied over the years in recognition of the complexity of food security and other issues evaluations as defined by the international research community and those definitions showed variation. Cafiero et al. (2014) emphasized that to contribute to knowledge and to allow correct assessments, however, measurement should be valid and reliable, posing two fundamental but distinct problems regarding what is being measured and how it is done. Assessing validity and reliability of measures - metric (s) is particularly problematic in the social sciences, where the phenomena we wish to measure are often not directly observable. The definition of what is being measured may become confounded with its measurement to the point that use of different measures would imply adoption of different notions of the phenomenon being analyzed, an issue that could easily go unappreciated by less sophisticated readers. Confusion may thus arise, especially when dealing with complex constructs. Cafiero, et. al. (2014) also indicated that hundreds of indicators have been proposed, ranging from quantification of food supplies at the country level, to more or less detailed characterizations of food consumption at the household or individual level, and including measures of nutritional outcomes with respect to growth and nutritional deficiencies. Some of these indicators are presented as "measures" of food security, others are combined in various ways to produce "indexes" but questions remain regarding whether they can indeed be considered proper measures.

We conclude, based on the obtained analysis that the inadequacy of food consumption can be reliably measured at the country and family/household level that could be converted into energy requirements and compared whether they have access to enough food to fulfil normal nutrition and energy requirements. Research results provide strong evidence that the PAHUM also provides valid/reliable measurement of food insecurity and hunger for target population, household and their individual uses. As summarized by Cafiero, et al. (2014), the criteria we apply are those of validity and of reliability (which in turn includes accuracy and precision) in a framework that partly overlaps with the one proposed by Frongillo (1999). PAHUM considers and discusses basic ideas about measurement and criteria for establishing validity of measures on UNIT basis and then uses these criteria to structure an examination of the research results available to establish the validity of food security and self sufficiency measures.
Comparison of the Different Methods (UNIT) and Their Applications on Households

It is really hard to understand how realistic the obtained results would be since so much statistical evaluations and adjustments used on the food security evaluations, including Food Consumption Survey (FCS-HH) and Household Socio-Economic Survey (HSES-HH) Household Consumption Evaluation (HCE) analysis and we really do not know the error level within these adjustments and judgments - i.e., High physical activity levels (PAL) were assumed in calculating the AMEs (Adult Male Equivalent - Weisell and Dop, 2012) for youth and adults; infants, children, and elderly were assumed to have moderate physical activity levels, and their AME was adjusted relative to that of the high PAL adult male, (Bromage, et. al. 2019), from Harvard University). It should be pointed out here that twenty two years later of the PAHUM application (Weisell and Dop, 2012) used the adult male equivalent - AME concept and its application to Household Consumption and Expenditures Surveys (HCES) which has similarities with PAHUM (Hasimoglu - Copyright@1989) that opens up a discussion and brings questions - "Why not assuming moderate physical activity of each age intervals their average energy requirements? Why based only on Adult Male not female or average of male and female, their average energy requirements? Actually, criteria used and assumptions made seemed bias selections. Similarly, Dary and Inhof-Kunsch (2010) developed a guide (Guide outlines the steps necessary for estimating per capita (PC) intake of staple foods using - Household Income and Expenditure Survey- HIES data) the steps necessary for estimating PC intake of staple foods using HIES that data provide estimates food purchases, rather than individual food consumption. Foods are distributed within households based on energy requirements (there is no direct measure of intra-household food allocation in the HIES). They began by identifying where the following important variables used for estimating consumption of staple foods reside. General demographic characteristics and created household "Adult Equivalent Unit (AEU)"variable by using age and sex-specific energy requirements published by FAO in 2004. The 18-30 year old male will served as the referent population, and all other values are calculated by dividing each age/sex group by the male referent value. In order specifically to estimate the potential impact of fortification on women of reproductive age, multiply the per capita estimates by 0.79 (AEU for 18-30 year old women). They recommended that the same can be done in children by multiplying the estimate by the AEU for the specific age/sex group of interest which are not age and gender specific.

In 2013 Food Consumption Survey (FCS-HH), which conducted by the Mongolian University of Science and Technology ( $n=1017$ households comprising 4087 individuals), and pooled 2012 and 2014 independentlysampled survey waves of the Household Socio-Economic Survey (HSES-HH), which was conducted by the National Statistics Office (Ulaanbaatar, Mongolia) $(n=28,985$ households comprising 106,760 individuals) and (Bromage, et al. 2019) applied different methods, and pain taking different analysis and adjustments by using data from Mongolia, this study evaluated four approaches for 
estimating diet from household surveys: direct inference from per-capita household consumption; disaggregation of household consumption using a statistical method and the "adult male equivalent" method, and direct prediction of dietary intake. Per-capita household consumption overestimated dietary energy in single- and multi-person households by factors of 2.63 and 1.89, respectively. Performance of disaggregation methods was variable across two household surveys analyzed, while the statistical method exhibited less bias in estimating intake densities (per $100 \mathrm{kcal}$ ) of most dietary components in both of the surveys. Increasingly complex prediction models explained $54 \%$ to $72 \%$ of in-sample variation in dietary energy, with consistent benefits incurred by inclusion of basic dietary measurements.

Bromage et al. (2019) have also concluded that "Accurate household consumption measurements are a prerequisite for accuracy of the AME and statistical disaggregation methods that are evaluated in his paper; for the purpose of directly assigning dietary intake to individuals, per-capita household consumption measurements are less useful for multi-person households because they imply impossibly equitable intra-household distribution of food. They also concluded that improving precision is challenged by the fact the inclusion of highly predictive variables-household energy intake or household size-e.g., changes the interpretation of parameter estimates, such that they reflect effects on household composition rather than the addition of household members. In light of these observations, they find it inappropriate to categorically recommend one method/unit over another, or to recommend against estimation entirely to focus more on measuring diet directly.

In another research conducted by Karageorgou, et al. (2019) from Friedman School of Nutrition Science and Policy, Tufts University, and University of Cambridge jointly evaluated data from the 2011-2012 Bangladesh Household Integrated Survey (BIHS), which included household-level consumption data (5,503 households) and individual-level dietary data based on $24 \mathrm{hR}$ from these households (22,173 participants). Household and 24hR estimates were standardized and harmonized for 33 dietary indicators, including 9 food groups, total energy, 8 macronutrients, and 15 micronutrients. Individual consumption was estimated from household data using two approaches, the Adult Male Equivalent (AME) and per capita (PC) approach. Karageorgou, et al. (2019) reviewed the research studies of (Kelly et al.1991; Naska, et al. 2009; Claro, et al. 2010 and Khatipzadeh, et al. 2016) referred to studies and stated that up to now, most global analyses have evaluated only single dietary factors or have used data on crude household expenditure or national food supply estimates that do not adequately capture individuals' actual consumption levels. Concluded that in this national survey, established methods and metrics for estimating individual level intakes from household surveys produce overestimation of intakes of nearly all dietary indicators, with significant variation depending on the dietary factor and modest variation depending on individual characteristics. [i.e., Younger adults (20-44 years) generally had higher consumption levels compared to other ages and in contrast to AME, the PC estimates often produced higher overestimation in women than men]. Above findings suggest a need for new methods to estimate individual-level consumption from household survey estimates. PAHUM may provide data analysis of individual dietary intakes assessment of the households and dietary habits and those can be used in comparative studies that are similar findings of Hasimoglu (2020) for Ethiopia, Nigeria and Tanzania; for India (2021) and also for Germany and Turkey (Unpublished-2021) on their grain production sufficiency evaluations on PC vs. PAHU).

Agricultural, Food/Energy Production Estimations and Predictions on Error Bound PC

One of our aims of study on the development of PAHUM was to provide insights into how the situation may develop to 2030-2050-era. FAO (2012) summarized based on the exogenous assumption that world GDP will be 2.5-fold the present one, and PC income will be 1.8-fold in 2030. All projections are surrounded in uncertainty; but expected developments in food and feed demand are subject to less uncertainty than other variables, particularly demand stemming from novel uses of global agricultural products and the underlying land and water resources requirements. i.e., the use of such products as feed-stocks for the production of bio-fuels has been growing in importance: this is the case of maize use for ethanol in the US, of sugar cane in Brazil, of vegetable oils and cereals in the EU to produce biodiesel and ethanol. Should such trends continue, bio-fuels could prove to be a major disruptive force, possibly benefiting producers but harming low-income consumer.

World average PC availability of food for direct human consumption, after allowing for waste, animal-feed and non-food uses, improved to $2,770 \mathrm{kcal} /$ person/day (Adult) in 2005/2007 (FAO, 2012). FAO's mean recommendation is $2600-2700 \mathrm{kcal} / \mathrm{PC}$ is the optimum total energy requirement for an adult. Thus, in principle, due to disregarding age and gender food consumption differences on PC evaluations there is sufficient global aggregate food consumption for nearly everyone to be well-fed. The claim is that, yet this has not happened: some 2.3 billion people live in countries with under $2,500 \mathrm{kcal}$, and some 0.5 billion in countries with less than $2,000 \mathrm{kcal}$, while at the other extreme some 1.9 billion are in countries consuming more than $3,000 \mathrm{kcal}$ because food consumption is not evenly distributed. The reasons are fairly well known: mainly poverty (Especially in rural areas), which has many facets, but is in many low-income countries linked to failures to develop agriculture and limited access to food produced in other countries (FAO, 2012). However the evaluations on PAHUM (Considering, 19.4 percentage unit error for each PC-Figure 1.) indicate that there is food to supply sufficient energy for almost everyone receives less than $2000 \mathrm{kcal} / \mathrm{PC}$ countries $(0.5$ million $)$ that may go up to $2400 \mathrm{kcal}$ close to recommended $2600 \mathrm{kcal} / \mathrm{PC}$ and here the problem is distribution of the food supply especially in the rural areas of developing countries.

Specifying quantitative targets will clarify the scope of the challenges that agriculture must face in the coming decades, focus research and policy on achieving specific outcomes, and ensure that sustainable intensification efforts lead to measurable food production and consumption, demand (On UNIT basis) and agriculture environmental relations improvements. Below findings 
may confirm the above statements of Hunter, et al (2017). Early studies and estimations (NRC, 1989; Torun, 2001 and FAO, 2005) indicated that the average allowance for men of reference size - moderate activity $(77 \mathrm{~kg} / 23$-year old male) is 2,300 kcal/day; for women $(58 \mathrm{~kg} / 23$-year old), it is $1,900 \mathrm{kcal} / d a y$. A normal variation of $\pm 20 \%$ is accepted as for younger adults. The requirements of persons beyond age 75 are likely to be somewhat less as a result of reduced body size, REE, and activity (NRC, 1989) that need to be considered. Estimates range from 1,600 to 2,400 calories per day for adult women and 2,000 to 3,000 calories per day for adult men. (Averaging 2,400 - 2,500 $\mathrm{kcal}$ 20-24-year old $\mathrm{M} / \mathrm{F}$ which is the average value given for $\mathrm{PC} / \mathrm{kcal} / \mathrm{d}$ ). Within each age and sex category, the low end of the range is for sedentary individuals; the high end of the range is for active individuals. Due to reductions in basal metabolic rate that occur with aging, calorie needs generally decrease for adults as they age.

On the other hand, (Alexandratos and Bruinsma, 2012) have made past and future food production projections on PC/kcal/d basis. These are: Year and $\mathrm{kcal} / \mathrm{d} / \mathrm{PC}$ respectively: Year 1990 - 2,627; 2007- 2,772; 2015 - 2860; $2030-2960$ and $2050-3,070$. It is really hard to justify the future projections which seem high especially for 2030 and 2050. Their, statement was that "The projections presented reflect the magnitudes and trajectories they estimated the major food and agriculture variables may assume in the future; they are not meant to reflect how these variables may be required to evolve in the future in order to achieve some normative objective, e.g., ensure food security for all, eliminate undernourishment or reduce it to any given desired level, or avoid food overconsumption leading to obesity." However, the evolving demographic picture may also impact the development prospects, food/energy demand when evaluated on PAHU basis and perhaps also the food security, in countries at the other end of the spectrum as compared to PC.

The calculated values of (Alexandratos and Brunisma, 2012) are recalculated on PAHU basis by considering the 19.4 percentage unit error coming from PC evaluations, (Figure 1.): Year and kcal/d/PAHU respectively, $1990-$ 3,136; $2007-3,309 ; 2015-3,414 ; 2030-3,534$ and 2050 - 3,665 which shows the gap and illustrates the PC evaluations do not reflect the reality and values are higher and not close to (NRC, 1989) and other literature recommended values (FAO, WHO and UNU, 2001). Concerning indicated findings above, author propose new directions for research and policy to help meet both sustainability and production goals which are based on developed PAHUM, because error bound PC projection evaluations are overestimating the major food commodity requirements.

Finally: Failure to recognize and address the problems inherent to error bound PC, "one-size-fits-all accept or reject" approach in food and other goods consumption calculations and projections (which are easy to use) may result in erroneous production and over consumption, demand, energy projections, misappropriations of resources and discontent among consumers. It may be extremely important to measure the food consumption of the families/households of developed and developing countries not on assumptions and statistical modelling (manipulations), instead on a standardized "UNIT" base that may make them comparable.

"Our analysis shows PAHUM evaluation may close the gap by illustrating the error coming from PC higher food demand and illustrate the real picture. Author certainly does not suggest that the world had run into constraints on the production side and had to live with durable declines in per capita or calculated PAHU output. Author's recommendation is that in the projections, the projected PAHU energy trend needs to be kept at minimum 2,600 $\mathrm{kcal} / \mathrm{d}-2,700 \mathrm{kcal} / \mathrm{d}$ and on BMR energy needs to be kept optimum, PC or PAHU-20-24-year old male; 1,700 $\left(1,694^{*}\right)$ and female $1,400\left(1,364^{*}\right) \mathrm{kcal} / \mathrm{d}$ (Table $1^{*}$ Calculated values ).

The WHAT Questions - Innovative Solution: Per Adult Human Unit Method $(P A H U M)=$ Age and Gender Corrected Per Capita (PC $\left.C^{a g c}\right)$

The PAHUM innovation is based on the human body and viable human survival questions: What are we unable to live without? What can we not avoid confronting? What common sum do we all share? What are the elements of the human condition? Existence of all people, in all diversity, across time and space (past and present) - cultures and civilizations carry something fundamentally is human physiology for survival depends on the food and its nutritive value including energy that it provides. Something, we can not renounce. We are all connected by the same basic elements - irrespective of who are we, where we were born or the kind of life we lead. The elements of the human condition are not a series of abstraction. They apply to everyone. You too...

So it can be said that it is in dealings with the basic elements of the human condition - biology/physiology and its elements energy metabolism that people become who and what they are. PAHUM aimed to call and take for action by all interested institutions, decision makers, politicians on Sustainable Development Goals (SDG) poor, rich and middle-income countries - to promote prosperity while protecting the environment that also aimed to recognize that ending poverty and first-target by 2030 then 2050-era.

Use of Per Adult Human Unit Method (PAHUM) = $\left(P C^{a g c}\right)$

Problem Statement Questions and Population Evaluations: The another question is how simply developed and developing countries adequately achieves a sustainable food future of its current world population (PC consumer) of 7.3 billion is expected to reach 8.5 billion by 2030, 9.7 billion in 2050 and 11.2 billion in 2100, according to a new (UN DESA, 2015) report, (World Population Prospects: The 2015 Revision; launched on 29.07.2015) in a manner that increases agricultural production, advances economic development and reduces pressure on the environment? Feeding the world population and eliminating the hunger brings more questions into the picture: "1. Are we using the right concept/methodology/metrics - (UNIT) to count the number of hungry people in the world? 2. The hunger numbers: are we counting right, how reliable are the suggested/applied methods/UNIT and food sufficiency evaluations by the national and international organizations (IFPRI, UNFAO, FiBL, IFOAM and others... ?), researchers and economists ..." The main point is how 
simply developed and developing countries adequately achieves a sustainable food future of SDGs and its 2030 , 2040 and 2050 population in a manner that advances economic development and reduces pressure on the environment that is evaluated on error bound Per Capita (PC) and other consumer metric(s) indicated above?"

Methodologies, Data Evaluations on PC and Suggestions: As indicated earlier, methodologies for producing consumption and production statistics and their evaluations suffer from a number of limitations and uncertainties that affect the overall reliability of the food data analysis. Lack of harmonization of definitions and regulations concerning how data are obtained and evaluation methods are used and presented further complicates the combination and comparison of data from different countries and regions (i.e, EU by EUROSTAT) and globally (i.e., by FAOSTAT, IFPRI) (FAO, 2011; FAO, WFP and IFAD, 2012; EUROSTAT, 2003 and 2015). As the data are based on the available supply per person (PC), they are not completely accurate in describing what people actually eat. That is why we can not call it data is based on standardized UNIT. However, the challenge is now to integrate sustainability into this picture. Sustainable development aims at the continuous improvement of the quality of life and well-being for present and future generations in a correct and complete form in its evaluation methodology (EU Commission, 2008). On the other hand investing in internationally comparable metric (s) for tracking progress toward the SDG goals is as important as agreeing on the goals and targets (Pingali and Risketts, 2014; Pingali, 2016). On the other hand, the purpose of error analysis of data based on PC and GDP PC arise two questions about the measurement (Cafiero, at al. 2014). First, is it "accurate," in other words, did the experiment, evaluation work properly and were all the necessary factors taken into account? The answer to this depends on the skill of the experimenter in identifying and eliminating all systematic errors. The second question regards the "precision" of the experiment. In this case the precision of the result is given: the experimenter claims the precision of the result is within 1.0 to 5.0 percent.

It should be highlighted here that at present, we are trying simply to find the right answer with the wrong unit/metrics, which is PC. In our data reporting process we must all go beyond what makes us good what makes us right: - As scientists we have to eliminate the error from the beginning at the planning stage. - While we are making the policy decisions in a narrow margin of test significance levels, we do not consider the minimum 19.4 percentage unit unintended error (Figure 1.) coming from the use of PC evaluations in our econometrics evaluations. - In exploratory scientific experiments a 5\% significance level is typically used. We can tolerate 1:20 chance of false alarm, since the cost of being wrong is low. - A low level of 5\% might be suggestive. - A level of $1 \%$ compelling and $0.1 \%$ convincing. - This is important for interpretation of the results. Some times apparent implausible coefficients remain statistically significant despite careful efforts at specification when we use PC.

Technical Focus on PAHU vs. PC Metrics: Approaches to validating food security metrics are as varied as the conceptualizations of the measurement tools themselves. The literature documenting the development and validation of recent experience-based measures reflects this divergence in approaches. It is critically important we monitor societal progress and design responsive policies to 21 st century challenges, such as climate change, the marginalization of more than a billion people, resource depletion (Agricultural production-food) and emerging pollution-driven health crises. We need reliable metrics to know how we are performing on the yardsticks of our economy, sustainability and social harmony (Kumar, 2019). As indicated earlier, Hickel, (2015) criticized the FAO's Food Security PC methodology framework and its recent revisions of the methodologies and asked are we using the right methodology to count the number of hungry people in the world? Are we really going in the right direction to end hunger? Hickel (2019) also raised the problem indicating that the vast majority of new income is being captured by the rich, and particularly by the global North $\$ 40,000 \mathrm{PC} / \mathrm{Y}$ (Including food). Only a very small share of it (about $5 \%$ ) goes to the poorest $60 \%$ of humanitySouth, despite the fact that they provide the majority of the labour and resources that go into the global economy, $\$ 5,000 \mathrm{PC} / \mathrm{Y}$ (Including food). As a consequence, the incomes of the rural poor have not grown enough to lift them out of poverty (to eliminate the hunger) - not by a long shot. That's author's contention, and that's the issue we need to confront. Even though it is out of our concerns for this article it should be indicated that the COVID-19 pandemic has pushed the developed and especially developing countries into a recession that seems like be worse this year and following years than the 2008 global financial crisis. We need to face up to these facts.

Lastly, as indicated above, IMF head Christine Lagarde, Nobel Prize-winning economist Joseph Stiglitz, and MIT professor Erik Brynjolfsson stressed that as the world changes, so too should the way we measure progress (Thomson, 2016; Thaller, 2016). While the principle is simple in practice, it becomes evident how such an indicator could lead to misrepresentations or mismeasurements. In fact, its creator, Kuznets, warned us against the limitations of GDP-PC. We clearly ignored those warnings and distorted GDP-PC, from a measure of macroeconomic activity, to a measure of welfare of a country (Esposito and Trence, 2016). Again as indicated, yet the international system basically continues on a business-as-usual basis with bureaucracies pursuing their day-to-day work and protecting their privileges. There are periodic call for changes, but do not translate into plans for action most of the time.

The HOW Question and Answer: Per Adult Human Unit Method = Age and Gender Corrected Per Capita $\left(P C^{\text {agc }}\right)^{l}$ PAHUM $=\left(\mathrm{PC}^{\mathrm{agc}}\right)$ introduces cutting-age innovation technique, such as human centred design as indicated above - Presented concept and lean start up to create evaluation "HOW" model presents its logical findings. $\mathrm{PAHUM}=\left(\mathrm{PC}^{\mathrm{agc}}\right)$ evokes innovation playgrounds of the researchers of EU/USA and international academicians and research institutions which based on:

1. Nutrition and Energy Expenditure for Human Survival and Productivity*: Method deals with primarily the requirement for a standard reference individual - UNIT (20-24-year-old M/F = PAHU) Basal Metabolic Rate (BMR) as base. BMRs are also calculated for each "5 - 
year-interval" age-groups. An age group of 20-24 was chosen as PAHU (Per Adult Human Unit) or reference person for both male and female.

2. Age \& Gender Structure of a Population/Target Group: Selected method design correlates to deviant anthropometry that includes defined age and sex structure along other effecting factors (Body weight, height, body frame, pregnancy environmental temperature etc.,) affecting BMR.

3. Selected Anthropometric Criteria**: Cut-off points for indicators were selected carefully, compared to most recent research results.

4. Calculation Procedure of PAHU for the age groups' BMR is based on long term studies of German scientists: $\mathrm{c}=$ $\mathrm{bW}^{\mathrm{n}}$ or $\log \mathrm{c}=\log \mathrm{b}+\log \mathrm{w}^{\mathrm{n}}$; here $\mathrm{c}=\mathrm{kcal}: \mathrm{w}^{\mathrm{n}}=$ metabolic size and $\mathrm{c} / \mathrm{w}^{\mathrm{n}}=$ statistical constant $\mathrm{b}$ is Each age group - BMR $(\mathrm{kcal})=70(\mathrm{~W} \mathrm{~kg})^{0.75}($ Brody, 1945; Kleiber, 1947; 1961)

5. Conversion Factor Calculation $=$ Male or Female BME kcal/d of the age groups: (divided by) 20-24-year old (PAHU) Male or Female BME kcal/d and results are tabulated for each age group (Table 1.) and PAHU versus PC evaluations and error level illustrated (Graphic 1).

BMR calculations compared to previous and the most recent calculation methods and research results (FAO/WHO, 1973a,b; FAO, 1981a,b; Durnin, 1981; WHO. 1985; FAO, WHO and UNU, 2001; FAO, 2011 and 2012). It should be indicated here that BMR is important for the human survival because eight years after the development of the PAHUM; 1993 Economics Nobel Prize winner, Fogel, in 2000 used the terminology "technophysio-evolution" in his evaluations, concluded that BMR plus energy used for productivity of human beings are essential elements of macro economic production and food production/consumption of the population (Consumer). The method and its practical application targeted to a wide range of users: 1. Policy-makers and technical staff in government ministries; 2. Members of NGOs, and 3. Researchers, academicians and private research institutions of developed and developing countries.

- BME requirements and calculated conversion factors can also be calculated and tabulated for each designated age-male and/or female (Age 0.1 to 99year) for each developing and developed country's populations (i.e., Vietnam, USA, Turkey and Germany) that will help to minimize and eliminate the error level due to young and older age groups and gender including body frame differences. BME Requirements and Calculated Conversion Factors of the Age Groups are presented in (Table 1.) and error level illustrated in (Figure 1.) that requires digitalization of the method and data collection for more detailed analysis.

- Since we had already celebrated "International Year of Family Farming" in 2014 and highlighted the hunger issue was the main subject, we have to watch that birth rates are falling, population growth has slowed down and the population as a whole is ageing healthy. Far reaching changes have taken place in family structures including farming families. Most importantly, economic growth itself is correlated to the age/gender and family/household structure of the population of each country on earth. Please see: "Rethinking on Household/Population Anthropometric and Real Food
Consumer Demand Evaluations of Target Populations (Here is EU) by Using Per Capita (PC) versus Per Adult Human Unit (PAHU) Method = /1999-20102020", (Hasimoglu, S. and V. Aksakal, 2015). http://www.davidpublisher.org/Public/uploads/Contri bute/55f90ce89e1a9.pdf

- Population data source - International data base https://www.census.gov/datatools/demo/idb/informationGateway.php

- PAHUM aims food system correction, transformation considering consumption, food supply, sustainability and socioeconomic outcomes on UNIT basis and inviting national action in a globalized world.

Preliminary Findings on PAHUM vs. PC

PAHUM $=\mathrm{PC}^{\mathrm{agc}}$ is "innovative": It improves the data validation process by providing an alternative to the current "One size fits-all' - PC, accept or reject approach. Innovative action: If all the food calories available in the world today were equally distributed across the projected 9 billion in 2050 and no food calories were lost between the farm and the fork. Those calories would still fall short of the FAO's "average daily energy requirements" 2,300 $\mathrm{kcal} \mathrm{PC} / \mathrm{d}$ by more than $200 \mathrm{kcal} \mathrm{PC} / \mathrm{d}$. If the current rate of food loss and waste were to remain in 2050, the gap would grow to more than $900 \mathrm{kcal}$ PC/d (FAO, $2015 \mathrm{a}, \mathrm{b})$. It has been re-projected on PAHU that the gap may still be $443.8 \mathrm{kcal} \mathrm{PAHU} / \mathrm{d}$ in 2050 not $900 \mathrm{kcal} \mathrm{PC} / \mathrm{d}$ as predicted by FAO. It is "applicable": It standardizes developed/developing nations or target households target populations that will make them comparable. The "relevance": Recent stochastic global population projections based on PC also yield wide error bounds. Our interest is in the particular dependence of the pattern of final demand on the size and structure of consuming target populations on UNIT basis. It is proven that PAHUM can be used in minimum 12 applicable different economic, social, environmental, political, demographic, food sufficiency evaluations fields (Hasimoglu, 2018; Hasimoglu and Aksakal, 2015; Hasimoglu, 2021).

Recalibration of developed and developing countries' families and households PC population is important for their social, economic, food security and environmental sustainability. Misidentified UNIT (PC) for measurement would not give correct results and if one installs correct assumptions on the wrong unit, the falls results will start following each other. Definition of consumer - one that consumes, especially one that acquires goods (Including food) or services for direct use or ownership rather than for resale or use in production and manufacturing. In order to properly evaluate a community/target population, household or consumers for the best location for consumables, one must know the demographic profile of the potential consumers (i.e., one day to one year old baby need baby food and diaper, on the other hand $80+$ year old need healthy food and sometimes grownup-diaper also) on unit basis but different sizes and amounts and on PC basis those are not comparable.

Comparison of the Different Methods (UNIT) and Their Applications on Households

Sustainable development starts with well fed, educated and healthy children. Safe and well fed households sustainable societies are, in turn, essential for the future of children and youth. It is increasingly recognized that a 
sustainable households of EU28 (496 million population, 120 million <20-year (teenagers 16-19 who were not living with parents $-29.7 \%$ are at significantly higher risk of poverty/social exclusion) will require a global shift in evaluation of increasingly unsustainable patterns of food consumption and production evaluations. "Place Based Approach" of the PAHUM is a call to action for researchers, decision-makers of EU to invest in children/youth's rights and well-being as an integral means to achieving sustainable economic development that starts within a well fed household. The effect of social climate change can be seen in the health and well-being of children and young people and also elderly. While most children are doing well, there is evidence of worsening or unacceptably high levels of nutritional deficiency problems in elderly also.
Author's research results below has shown that, two equally numbered households (Chad and Turkish, 6 - PC each) with different age groups were compared on PAHUM, Adult Equivalent (AE) and PC to evaluate the household staple food (grain/cereal) consumption/ sufficiency to assess the nutritional status of individuals according to age groups and anthropometric criteria and the adequacy of staple food (cereal), energy and nutrient intakes. PAHU gave more accurate and precise results. The data then compared to desired food and nutrition goals especially for children. Below explained analyzed household data even provided information on the distribution of target food (Grain/cereal) within the household age groups based on the calculation of age groups conversion factors (Table 1).

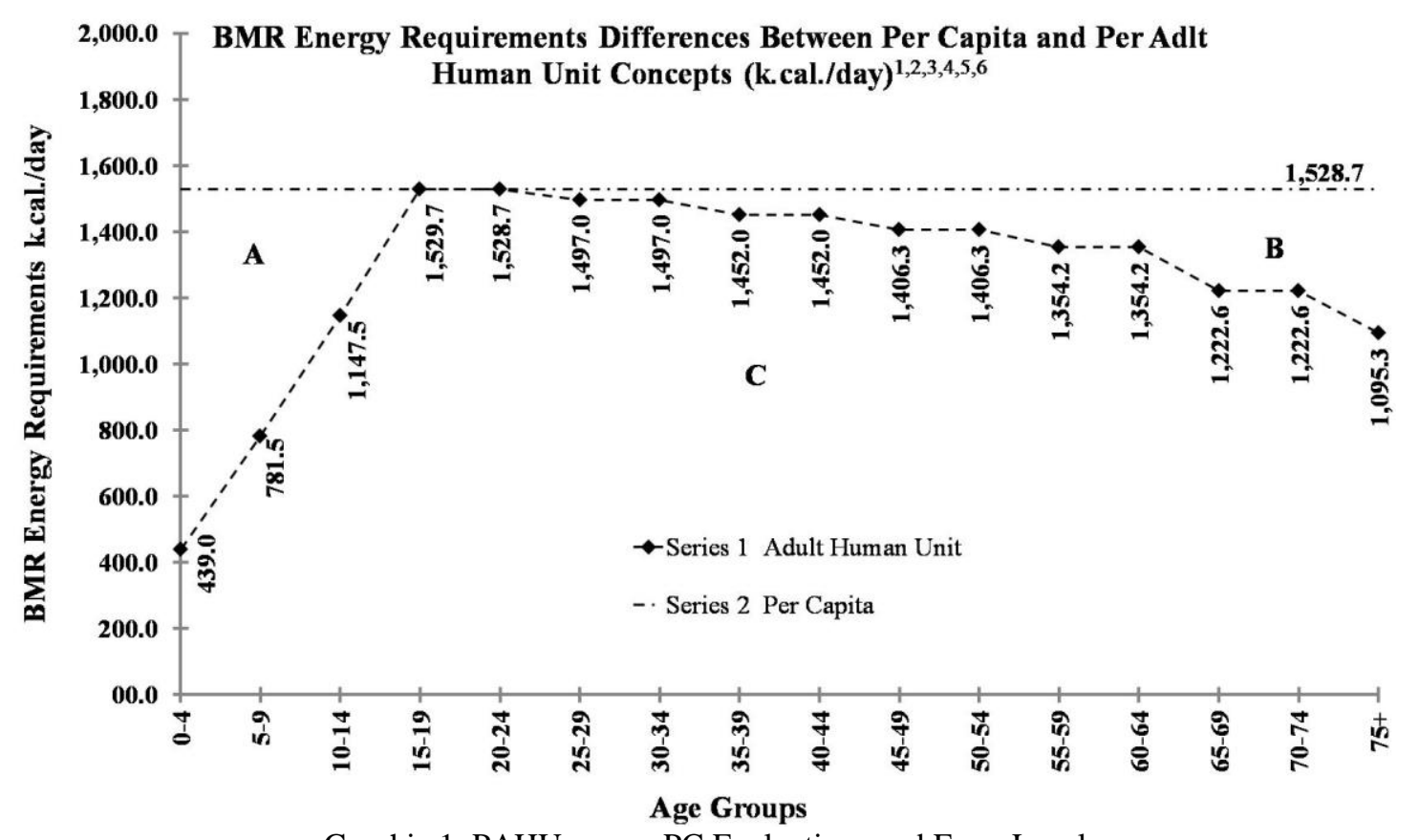

Graphic 1. PAHU versus PC Evaluations and Error Level

1. PAHU, BMR energy requirements are the average of males and females of each age group, (Table 1. PAHU calculated conversion factors). 2. Rectangle is $\mathrm{PC}$ area $=(\mathrm{A}+\mathrm{B}+\mathrm{C})=100 \%$; Triangle $\mathrm{A}$ is $<20$ - age group $=7.6 \%$ of rectangle; 3 . Triangle $\mathrm{B}$ is $>20-24$ age group $=11.8 \%$ of rectangle; 4 . Difference from $\mathrm{PC}=\mathrm{A}+\mathrm{B}=7.6+11.8=19.4 \%$ (Error level); 5 . PAHU $=(\mathrm{A}+\mathrm{B}+\mathrm{C})=100-(7.6+11.8)=80.6 \%$ of $\mathrm{PC} ; 6$. Error level (19.4 percentage units).

Table 1. BME Requirements and Calculated Conversion Factors of the Age Groups ${ }^{2}$

\begin{tabular}{l|cccccc}
\hline \multirow{2}{*}{ Age Groups } & \multicolumn{2}{|c}{ Calculated BME ${ }^{3}$ Requirements kcal/day } & \multicolumn{3}{c}{ PAHU Conversion Factors* } \\
\cline { 2 - 6 } & Male & Female & Average & Male & Female & $\bar{X}$ \\
\hline $0-4$ & 445.1 & 432.7 & 438.9 & 0.262 & 0.317 & 0.287 \\
$5-9$ & 782.1 & 780.5 & 781.4 & 0.462 & 0.572 & 0.511 \\
$10-14$ & 1138.6 & 1156.1 & 1147.4 & 0.672 & 0.848 & 0.751 \\
$15-19$ & 1571.5 & 1487.9 & 1492.5 & 0.974 & 1.091 & 0.976 \\
$20-24^{1}$ & 1694.0 & 1363.3 & 1528.7 & 1.000 & 1.000 & 1.000 \\
$25-34$ & 1659.0 & 1336.0 & 1494.5 & 0.979 & 0.979 & 0.980 \\
$35-44$ & 1609.0 & 1295.0 & 1452.0 & 0.950 & 0.950 & 0.950 \\
$45-54$ & 1558.5 & 1254.0 & 1406.3 & 0.920 & 0.920 & 0.920 \\
$55-59$ & 1473.8 & 1234.5 & 1354.2 & 0.870 & 0.906 & 0.886 \\
$60-64$ & 1473.8 & 1234.5 & 1354.2 & 0.870 & 0.905 & 0.886 \\
$65-74$ & 1354.6 & 1090.6 & 1222.6 & 0.800 & 0.800 & 0.800 \\
$75+$ & 1218.0 & 972.6 & 1095.3 & 0.719 & 0.713 & 0.716 \\
\hline
\end{tabular}

${ }^{1}$ Standard Adult Human Unit (Age 20-24) for male and female BME requirements are 1694.0 and $1363.36 \mathrm{kcal} / \mathrm{d}$ respectively, averaging 1528.7 kcal/d. ${ }^{2} \mathrm{PAHU}$ calculation = Population of the age group $\mathrm{x}$ Age group's conversion factor. Conversion Factor Calculation = Male or Female BME kcal/d : 2024-year old (PAHU) Male or Female BME kcal/d. ${ }^{3}$ Basal Metabolic Energy (BME) is the minimum energy cost of body process, representing the excess of endothermic over exothermic reactions in the body. *Conversion Factor Calculation = Male or Female BME kcal/d of the age groups: 20-24year old (PAHU) Male or Female BME kcal/d. Durnin, (1981) reported the BMR values for 20-24 year old male and females are 1715 and 1350 kcal/d respectively. FAO, (1981) also reported similar BMR values presented in Table 1. - Web page: http://www.fao.org/3/m2845e/m2845e00.htm 


\section{Results and Discussions}

Elimination of Inconsistencies of the Organic/Conventional Food Consumption, Production Evaluations of Family / Household on PAHUM vs. Error Bound PC and Adult Equivalent /Adult Male Equivalent - $\boldsymbol{A E} / \boldsymbol{A M E}$

Impact and its Results: Frequent evaluation of the methods and the systems of monitoring food security is necessary for generating continued interest by researchers, decision-makers/politicians. Last 30-year author is following the literature and there has been considerable interest among planners and policy makers in identifying cost-effective and time-efficient approaches to monitoring the food security status of the households of developed and developing countries.

Certainly, there are consistency problems not only among EU nations and its institutions but also at the international level that do not use the same definitions. These inconsistencies give too much space for arbitrary decisions that will damage the comparability of the family and household statistical data, along food consumption/demand population projections. Besides PC and PAHUM one of the most popular method of comparing families' consumption (Food-grain) and other criteria is the adult equivalent (AE) scale that was developed by Friedman long ago in 1935 (Friedman, 1952) which is a generalization of the income PC evaluations (Lambert and Yitzhaki, 2000). There are different approaches to convert the number of persons in the household to "adult equivalents" by developed concepts and formulas. Different formulae are used in discounting gender and elderly and counting children and adults at different scales: (EUROSTAT. 2003; EUROSTAT, 2008; OECD and JRC-EU Commission, 2013).

Different Adult Equivalent (AE) approaches are introduced by different researchers and institutions: (1). First adult in the house $=1$; other adults, $>13=0.5$ and child $(13$ or under $)=0.3$ ((OECD and (JRC-EU Commission, 2013);
(2). Baschiery et al. (2005) used adult equivalency scale when creating a poverty map for Azerbaijan with a World Bank project. Adult equivalent children aged below the age of six have been assigned a weight of 0.2 , children aged 712 have been assigned of a weight 0.3 , age 13-17 have been assigned a weight of 0.5 and a weight of 1.0 if the household member is older than 17 years and (3). UN approach was used (Wadan, 2012) to treat each child between the ages 0 and 14 as equivalent to half an adult and any person over the age of 14 as 1 adult. In another World Bank, Programmatic Poverty Assessment (Tedford, Capps and Havlicek, 1986) assumed a scale parameter of 0.8 (individuals of age 18 and below with no age groups) in $70 \%$ of the cost of an adult. None of the above researchers considered gender nor the $>$ 66 age group.

In order to compare the PC, PAHUM and AE grain consumption/demand evaluation two equally populated (6member) families from Chad and Turkey were selected with different age and gender structure. Results are summarized in (Table 2.) including brief summary of carbon dioxide emission of the families. Data indicates that both families yearly cereal (Grain) consumptions would be the same $(1,200 \mathrm{~kg} / \mathrm{Y}$ on the basis $200 \mathrm{~kg} / \mathrm{PCY}$ basis $)$ each on PC basis which does not consider the age and gender that may cause overestimation. On PAHU basis as compared to $\mathrm{PC}$ the grain savings are 340 and $160 \mathrm{~kg} / \mathrm{Y}$ for Abubakar $(860 \mathrm{~kg} / \mathrm{Y})$ and Celik $(1,040 \mathrm{~kg} / \mathrm{Y})$ families respectively. On AE basis the evaluations do not match neither of the evaluations and not even get closer and almost the half of the PC and $3 / 4^{\text {th }}$ of the PAHU evaluation amounts for Abubakar $(540 \mathrm{~kg} / \mathrm{Y})$ and Celik $(660 \mathrm{~kg} / \mathrm{Y})$ families. The inconsistencies of different criteria/methods and parameters (Three different $\mathrm{AE}$ evaluation) used by different scientists including PC and PAHUM were discussed for an eleven member Egyptian Family (Hasimoglu and Aksakal, 2015) gave similar results.

Table 2. The real world of two developing countries households*: Comparing Household - Aboubakar-Chad and Household-Çelik-East Turkey ${ }^{1}$ yearly grain $\mathrm{CO}_{2}$ emissions $^{1}$ on PC, AE and PAHU metrics/unit basis*** (Hasimoglu, 2014; 2018; Hasimoglu and Aksakal, 2015)

\begin{tabular}{|c|c|c|c|c|c|c|c|}
\hline \multicolumn{4}{|c|}{ Household Aboubakar } & \multicolumn{4}{|c|}{ Household Çelik } \\
\hline Gender (age) & $\mathrm{PC}$ & $\mathrm{AE}$ & PAHU & Gender (Age) & $\mathrm{PC}$ & $\mathrm{AE}$ & PAHU \\
\hline Woman (49) & 1 & 1.0 & 0.920 & Woman (65) & 1 & 1.0 & 0.800 \\
\hline Boy (15) & 1 & 0.5 & 0.974 & Man (45) & 1 & 0.5 & 0.920 \\
\hline Girl (12) & 1 & 0.3 & 0.848 & Woman (38) & 1 & 0.5 & 0.950 \\
\hline Boy (10) & 1 & 0.3 & 0.672 & Girl (18) & 1 & 0.5 & 1.091 \\
\hline Girl (7) & 1 & 0.3 & 0.572 & Boy (16) & 1 & 0.5 & 0.974 \\
\hline Girl (3) & 1 & 0.3 & 0.317 & Boy (9) & 1 & 0.3 & 0.461 \\
\hline Total & 6 & 2.7 & 4.303 & Total & 6 & 3.3 & 5.196 \\
\hline Grain reg. T/Y* & 1.2 & 0.54 & 0.86 & Grain reg. T/Y* & 1.2 & 0.66 & 1.04 \\
\hline $\mathrm{CO}_{2}$ emissions $\mathrm{T} / \mathrm{Y}^{* *}$ & 28.8 & 13.0 & 20.9 & $\mathrm{CO}_{2}$ emissions $\mathrm{T} / \mathrm{Y}^{* *}$ & 28.8 & 15.8 & 24.9 \\
\hline
\end{tabular}

* World average PC grain consumption (Hasimoglu, 2012, 2014a,b) is $200 \mathrm{~kg}$ and red meat consumption is $29.7 \mathrm{~kg}$; $* * \mathrm{Grain}: \mathrm{t}=\mathrm{Tons}$; $\mathrm{Y}=\mathrm{Year}$; PC $=$ Per Capita; AE = Adult Equivalents; PAHU = Per Adult Human Unit; AE: First adult in the house $=1$; other adults $>13=0.5$ and child $(13$ or under) $=0.3$; Gender is not considered nor the > 66 age group [EUROSTAT, $(1999 ; 2005 ; 2008) ;\left(\right.$ OECD, 2013)]; PAHU values, from Table $1 ; * * *$ CO $_{2}$ emissions: World average 4.8 Tons/PC value is used to calculate the household annual $\mathrm{CO}_{2}$ emission calculations (Values are from: Wikipedia, the Free Encyclopedia. 2015; Wikipedia. 2015; Union of Concerned Scientists. 2011). 
Table 3. Households Individual (PAHU) Family Members' Key Food Items (Grain/Cereal) Consumption/Partake Evaluation of Abubakar (Chad) and Çelik (Turkey) Households

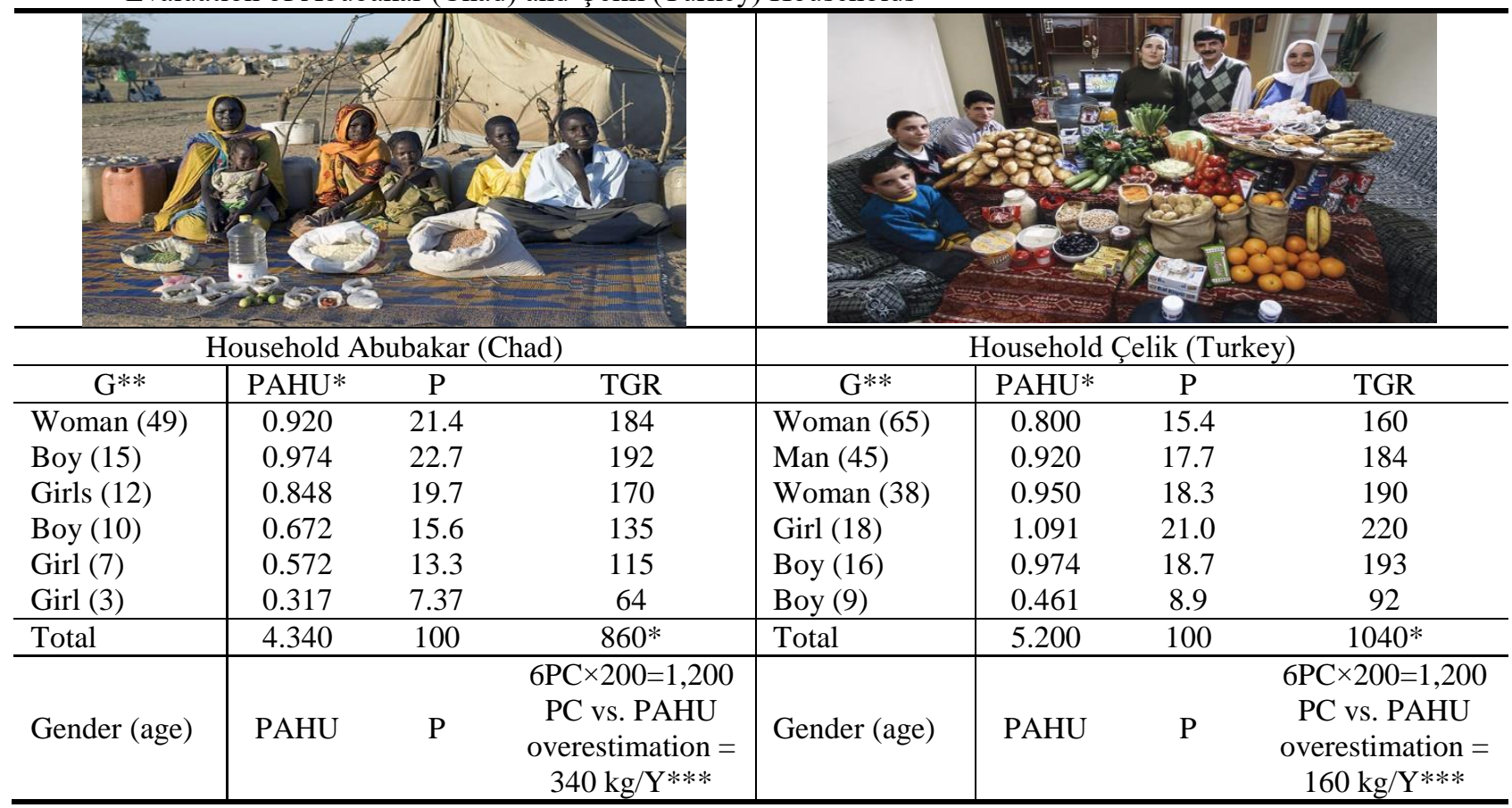

G: Gender (age), P: \% of total PAHU, TGR: Total grain requirement, kg/Y, *PAHU - From Table 1. Conversion Factors ; ** Hasimoglu and Aksakal (2015); Hasimoglu, (2021). *** World average PC grain consumption is $200 \mathrm{~kg} / \mathrm{Y}$ and $1,200 \mathrm{~kg} / \mathrm{Y}$ for both Abubakar and Çelik Families.

From the impact on environment, many argue that the household and not the individual (PC) is the more appropriate unit for measuring emissions also and on the PC basis, the picture looks different (Table 2.). Below findings indicate that PAHU household emission evaluations (20.9 and $24.9 \mathrm{~T} / \mathrm{Y})$ would be better and more sensitive unit values in reflecting the age and gender differences as compared to other evaluations (PC 28.8; 28.8 T/Y and AE 13.0 and 15.8 Y/T) units for the Ahmed and Celik families respectively.

On the other hand in developing countries (i.e., Turkey) especially in single and double households, consumption habits are different than those of large families. Differences in the feeding habits of this segment are outstanding. In small households, there is an increase in bespoke meals, ready-to-eat and frozen food consumption, as well as eating out. This change caused the producers to shape their products for this audience. The most important reason for the change was that food prepared family size that "Products were not suitable for the consumption habits of lonely people". Even this change has created a differentiation not only in the food sector, but also in the consumption of durable consumer goods and the real estate market (Bayüksel, 2013 and DJS Research, 2019) that requires a detail research. We should not forget that reviewed data indicate that large household size is widely regarded as a risk factor for malnutrition in developing countries, particularly not only for infants and young children also the elderly.

Impact: Individual Basic/Key Food (Grain/Cereal) Collective Consumption Estimation of Each Family Member/Partaker of the Households (Table 3.)

There are several limitations to the HCES (Household Consumption and Expenditures Survey) of food, most notably the difficulty of estimating the intra-household allocation of foods and therefore of quantifying the actual food intake of individual household members and their nutritional statues. As indicated above (Karegeorgou et al. 2018) concluded that established methods (i.e., PC and AME metrics-units) for estimating individual level intakes from household surveys produce overestimation of intakes of nearly all dietary indicators, with significant variation depending on the dietary factor and modest variation depending on individual characteristics. Methodology constructed in their analysis showed that current methods for estimating individual intakes from household-level data are problematic, yet it confirmed usefulness of the AME vs. the PC approach in better approximating dietary intakes for key populations, mainly children and women. FAO food balance sheets provide important information on average national food availability, but not on actual intakes or on heterogeneity within populations even within the target household (Kelly et al.1991). Khatipzadeh, et al. (2016) referred to Naska, et al. (2009) and Claro, et al. (2010) studies and stated that up to now, most global analyses have evaluated only single dietary factors or have used data on crude household expenditure or national food supply estimates that do not adequately capture individuals' actual consumption levels. These findings suggest a need for new methods to estimate individuallevel consumption from household survey estimates that PAHUM may be used as an alternative.

Another concern is the lack of information on the variability of consumption over time, making it difficult to estimate the distribution of usual consumption, and thus the prevalence of nutrient inadequacies or excesses. Research is needed to better understand both the strengths and the weaknesses of the HCES data when used to assess and plan intakes at the household and at individual levels. Further it should be indicated here that on the percentage unit representation of each PAHU within the family (According 
age and gender conversion factors - Table 1.), it is also possible to evaluate each household member's consumption amounts accordingly as long as total allocated or total consumed major/key food amount is known (Table 3) . Below (Table 3.) find the household grain consumption evaluation of each family member of Household Abubakar (Chad) - has 6 PC but 4.2 PAHU and Household Çelik (Turkey) - again 6-PC but 5.2 PAHU respectively due to age and gender differences. Each member's grain requirement is determined by considering their PAHU conversion factor percentage within total PAHU due to age and gender. On the basis of PC designated, projected grain consumption is $200 \mathrm{~kg} / \mathrm{Y} / \mathrm{PC}$, total PC grain consumption for both 6-member-families would be $1,200 \mathrm{~kg} / \mathrm{Y} / \mathrm{PC}$ each family regardless age and gender. On the basis of each family member's percentage unit share in PAHU it is possible to define (Calculate) the required total amounts $(200 \mathrm{~kg} / \mathrm{Y})$ come to $860 \mathrm{~kg} / \mathrm{Y}$ and $1040 \mathrm{~kg} / \mathrm{Y}$ respectively (Table 3.) and by using family member's percentage unit share in total PAHU that can be used to calculate/define each member's required amount. $\mathrm{kg} / Y$. i.e., Abubakar family 15-year old boy's share from PAHU total grain requirement $(860 \mathrm{~kg} / \mathrm{Y})$ is $192 \mathrm{~kg} / \mathrm{Y}$. Çelik Family 16-year old boy's share from total grain requirement $(1040 \mathrm{~kg} / \mathrm{Y})$ is $193 \mathrm{~kg} / \mathrm{Y}$ which is almost the same. On the other hand Abubakar 49-year old woman grain share from total is $184 \mathrm{~kg}$., but 65 -year old women from Celik Family's grain share from total is $160 \mathrm{~kg} / \mathrm{Y}$ illustrates the age differences due to less energy requirement with aging. In addition (Table 3.) shows the allocated grain differences between families/households and within families/households according age and gender. This evaluation approach based on PAHUM may also open the door for the nutrient deficiency evaluations of the whole family or individually for each member plus $\mathrm{CO}_{2}$ emissions may be calculated the same way by using the described procedure.

Finally, proposed metric (PAHU) can be used for food consumption adequacy, sufficiency and efficiency evaluations at the household or individual level and it possesses the analytic foundations required to determine their empirical validity as food security measures. In particular, there is basis to establish the reliability and the validity of the measures obtained in practice or to ensure comparability across applications. These results provide strong evidence that the PAHUM provides valid/reliable measurement of food insecurity and hunger for target population, household and individual uses. PAHUM household consumption measurements are more useful for multi-person households because they imply individual intra-household key food items share/consumptions according to family's age and gender distribution.

\section{Developed PAHU Addresses the Analysis of Following Problems and Conclusions}

How can global (Developed and developing countries) social policies be used to enhance social capacities for economic development by evaluating the population not on error bound PC or AE but PAHU/Gender and age corrected $\mathrm{PC}^{\mathrm{agc}}$, in the process, eroding the intrinsic values of the social ends that policy makers purport to address? A major economic growth and improved living standards, rapidly increasing demand for food and other goods that increases the $\mathrm{CO}_{2}$ emissions and other environmental concerns are the major issues facing the population that is compatible with the negative side of production, measured in terms of PC and family evaluations on Adult Equivalent units respectively. The idea to develop a single composite indicator - PAHU or Gender and age corrected $\mathrm{PC}=\mathrm{PC}^{\mathrm{agc}}$ has so far not taken into work list in scientific institutions. This deficiency may now be covered.

As indicated earlier, Albert Einstein ones put it "We can not solve problems by using the same kind of thinking we used to create them". Thus it is time to develop a new society-wide single composite indicator (PAHU) that describes welfare in more sophisticated way than old and primitive PC-GDP and/or PC organic/conventional food consumption/production (Cereal) or $\mathrm{PC}-\mathrm{CO}_{2}$-emission measure. This composite may also guide us in next decades towards sustainable world where economy does not exceed the global limits and endanger global ecosystems as today. PAHU $=\left(\mathrm{PC}^{\mathrm{agc}}\right)$ evokes innovation playgrounds of not only researchers, also the decision makers of the developed and developing countries. It can well be applied to every country's/target groups' organic/conventional food consumption evaluations, agriculture and environmental issues problems. In addition it may have the potential to have an impact on economic evaluations when Genuine Progress Indicator (GPI) and Sustainable Society Indicator (SSI) are used as basis for the societies-replacement of PCGDP that is needed for the development in economic reevaluations. The innovative action of $\mathrm{PC}^{\mathrm{agc}}$ may require shifts in government planning by adding its ecological impacts into the equation. In addition, PAHU/PC ${ }^{\text {agc }}$ method evaluation may be used internationally. Here EU28/Candidate Countries and Europe (After January $31^{\text {st }}$, 2020 it is EU27) evaluation indicated that it has practical applications and impact in highlighting many issues and can be used in evaluation in many areas (Twelve practical application in different areas), (Hasimoglu 2014 a,b; 2018 and 2019).

A systematic assessment of the program's impact and potential through PAHUM plus a household and farm survey-based evaluation would add greatly to the value of the anecdote land impressionistic evidence based on accumulated PC judgements. For countries that wish to initiate a dialog about national food security policy and the limitations of self-sufficiency, such a feasible and relatively simple modelling exercise may serve as a useful point of departure. The rapid growth in population and urbanization will increase the demand for more food as well as for industrial and other uses of cereal especially in developing nations.

Some policy or technology changes may have unintended consequences in the system (Like, recently very quickly spreading global corona virus epidemic) and require closer examination of system interactions, including demographic structure, human behaviours related to adoption and use of new inputs (Anatomical structure of the population: i.e., Body weight of USA and Vietnam populations differs and effect the energy requirements), products, and processes that should address issues of product acceptance and consumer trust in the food system.

Finally; reversing the current alarming trends will require not to make the evaluations on error bound Per 
Capita (PC - which can not be called UNIT) instead may using innovated Per Adult Human UNIT Method (PAHUM) which is more precise approach to build resilient agriculture food systems that are socially, environmentally and economically sustainable. Application and making the evaluations on PAHUM focuses on experiences and strategies that can both build food system resilience and help prevent conflict. The approaches and the methods used in economic and food security and other areas' evaluations are different, but the reasons and goals are actually the same. In general, author also noticed that the general economic and legal framework today basically promotes the destruction of the earth. So we need a framework that enables evaluations on UNIT* basis to work in a way that does better for everyone on earth. That is why we should be involved in building back fairer economies on accepted UNIT basis.

Knowingly insisting on the unintended error coming from PC approach does not justify statistically tested results of the PAHUM projections. Considering its philosophy and the ethics behind it, "Everybody is making the same error why not me" does not justify its excuse.

\section{Acknowledgement}

Author is thankful to Prof. Dr. Gerold Rahmann (Director of the Thünen Institute of Organic

Farming of the German Federal Research Centre vTI, Hamburg, Germany and Board

member of IFOAM) for his support on the PAHUM its practical application and his kind

cooperation, support at international arena and my scientific activities.

\section{References}

Aertsens J, Verbeke W, Mondelaers K, Van Huylenbroeck G. 2009. Personal determinants of organic food consumption: a review, British Food Journal, Vol. 111 Issue:10, pp.11401167. Available from: https://orgprints.org/16912/1/ Aertsens_2009_Personal_determinants_of_ORGANIC_FO OD_CONSUMPTION.pdf (Accessed 30.04.2020).

Alexandratos V, Bruinsma J. 2012. World agriculture towards 2030/2050: the 2012 revision. Perspective Studies Team FAO Agricultural Development Economics Division. ESA Working Paper No. 12-03. Available from: http://www.fao.org/3/a-ap106e.pdf (Accessed 07. 11.2019).

Arbenz M. 2011. "Global Organic Agriculture and Turkey." NTSR - Growtech, Eurosia Fair. Available from Personal Communication, https//www.growtech.com.tr (Accessed 5.12.2011)

Baschieri A, Falkingham J, Hornby D, Hutton, C. 2005. Creating a Poverty Map for Azerbaijan. Washington DC: Azerbaijan. Policy Research Working Paper; No. 3793. https://openknowledge.worldbank.org/handle/10986/8545 (Accessed 5.12.2014)

Benton C. 2019. What Is Per Capita? Investopedia. Available from: https://www.investopedia.com/terms/p/percapita.asp (Accessed, 27.04.2020)

Bayüksel ÖŞ. 2013. Düşük Hane Sayısı Tüketime Engelmi? Capital Dergisi. Available from: Available from: Capital Dergisi. http://www.capital.com.tr/dusuk-hane -sayisitüketime-engel-mi-hab..._(Accessed 16.05.2015).

Brody S. 1945. Bioenergetics and Growth. New York: Reinhold Publishing Corporation. New York.
Bromage S, Bernard RW, Rick-Edwards JW, Ganmaa D, Tsolmon S, Tserendejid Z., Odbayar T-O, Traeger M, Fawzi WW. 2018. Comparison of Methods for Estimating Dietary Food and Nutrient Intakes and Intake Densities from Household Consumption and Expenditure Data in Mongolia. Nutrients. 2018 Jun; 10(6): 703. Published online 2018 May 31. doi: 10.3390/nu10060703; PMCID: PMC6024672; PMID: 298575362018 Aug 27;13(8): e0202831. doi: 10.1371/journal.pone.0202831. eCollection 2018. Available from: (Accessed 20.11.2019)

Cafiero C, Melgar-Quinonez HR, Ballad T, Kepple AW. 2014. Validity and reliability of food security measures. First published: 18 November 2014. Available from: http://onlinelibrary.wiley.com/doi/10.1111/nyas.12594/full (Accessed 21.10.2019).

Claro RM, Jaime PJ, Lock K, Fisberg RM, Monteiro CA. 2010. Discrepancies among ecological, household, and individual data on fruits and vegetables consumption in Brazil. Cad Saude Publica. 2010. November; 26(11): 2168-76. 10.1590/S0102311X2010001100018. Available from: https://www.scielo.br/ scielo.php?pid=S0102-311X2010001100018 \&script=sci_arttext (Accessed 09.05.2020).

Carebot, 2020. Metrics, Measures and Indicators. Avilable from: https://thecarebot.github.io/metrics-measures-and-indicators/ (Accessed 02.10.2020).

Dary O, Imhoff-Kunsch B. 2010. Guide to estimating per capita consumption of staple foods using Household Income and Expenditure Survey (HIES) dataECSA/A2Z. Monitoring and Evaluation Workshop Kampala, Uganda July 5-7, 2010. https://www.spring-nutrition.org/sites/default/files/ a2z_materials/508_guide_estimating_per_capita_consumpti on.pd (Accessed, 20.8.2020).

DJS Research. 2019. Global Market Research TGI - (Target Group Index). Available from: https://www.djsresearch.co.uk/ glossary/item/TGI-Target-Group-Index (Accessed 11.10. 2019).

Durnin JVGA. 1981. "Basal Metabolic Rate in Man." ESN: FAO/WHO/UNUEPR/81/5. Available from: http://www.fao.org/ 3/contents/3079f916-ceb8-591d-90da-02738d5b0739/M2845 E00.HTM (Accessed 16.06.2015).

Esposito M, Trence T. 2016. Why we need to complement, rather than replace, GDP. World Economic Forum. Available from: https://www.weforum.org/agenda/2016/04/why-we-need-tocomplement-rather-than-replace-gdp (Accessed 29.08.2019).

EU Commission. 2008. "Communication from the Commission to the European Parliament, the Council, the European Economic and Social Committee and the Committee of the Regions on the Sustainable Consumption and Production and Sustainable Industrial Policy Action Plan $\{$ SEC(2008) 2110\} \{SEC(2008) $2111\}$ and also Proposal for a Community Lisbon Programme 2008-2010-COM(2007) 804." Renewed EU Sustainable Development Strategy, Council of the EU. Available from: http://eur-lex.europa.eu/legal-content/EN/ALL ;ELX_SESSIONID =cGyCJgGZQMcpHGQxY4yQXk2HFsbZwVQvh9vWcms 2gCDJpSNGGxv0!-330301153?uri=CELEX:52008DC0397 (Accessed 15.02.2015).

European Commission, 2019. Organic farming in the EU. A fast growing sector. No 13, March 2019. Available from: https://ec.europa.eu/info/sites/info/files/food-farmingfisheries/farming/documents/market-brief-organic-farmingin-the-eu_mar2019_en.pdf (Accessed 30.04.2020).

EUROSTAT. 2003. "Household Expenditure in the EU15; Household Budget Survey in EU27." Available from: http://ec.europa.eu/eurostat/cache/metadata/Annexes/hbs_es ms_an1.pdf (Accessed 10.05. 2015).

EUROSTAT. 2008. "Pocketbooks. Food: from Farm to Fork Statistics." Office for Official Publications of European Communities, KS-30-08-339. Available from: http://ec.europa.eu/ eurostat/web/products-pocketbooks/-/KS-30-08-339 (Accessed 22.06. 2012). 
EUROSTAT. 2015. “Air Pollution Statistics.” Available from: http://ec.europa.eu/eurostat/statistics-explained/index.php/ Air_pollution_statistics (Accessed 17.05.2015).

FAO.1981a. Metabolic Rate in Man - Available from: http://www.fao.org/3/m2845e/m2845e00.htm (Accessed 31.07. 2019).

FAO. 1981b. 4. Energy Requirements of Children and Adolocents. Chapters \#1-9. Available from: http://www.fao.org/ 3/y5686e/y5686e03.htm\#TopOfPage (Accessed 31.07.2019).

FAO. 1981c. The State of Food and Agriculture. Alleviating Rural Poverty. FAO. Agr. Series. No: 14. ISBN 92-5-1012016, Rome, Italy. https://www.fao.org/3/ap661e/ap661e.pdf (Accessed 31.07.2019).

FAO. 2004. FAOSTAT data. Available from: http://apps.fao.org/ faostat/form?collection=FBS\&Domain=FBS\&servlet=1\&hasbu $\mathrm{lk}=0$ \&version $=$ ext\&language $=\mathrm{EN}$ also in $\mathrm{http}: / / \mathrm{www}$.fao.org/ 3/y5825e/y5825e0c.htm\#TopOfPage (Accessed 04.10.2019).

FAO. 2005. 4. Energy requirements of children and adolescents. Available from: http://www.fao.org/3/y5686e/y5686e06.htm (Accessed 26.02.2020).

FAO. 2011. "Women in Agriculture: Closing the Gender Gap for Development." The State of Food and Agriculture. Available from: http://www.fao.org/docrep/013/i2050e/i2050e.pdf (Accessed 21.03.2015).

FAO. 2015a. FAOSTAT - 2015. Available from: http://www.fao.org/ faostat/en/\#home (Accessed 20.02.2020).

FAO. 2015b. Prospects for food and nutrition. 2.1 The broad picture: Historical developments and present situation. Available from: http://www.fao.org/3/y4252e/y4252e04.htm (Accessed 14.05.2020).

FAO/WHO. 1973a. Human Energy requirements. Prakash Shetty. Chief. Nutrition Planning, Assessment \& Evaluation Service (ESNA). Food \& Nutrition Division. Rome and Geneva Available from: http://www.fao.org/3/y5686e/ y5686e03.htm (Accessed 10.03.2020).

FAO/WHO. 1973b. Energy and protein requirements: Report of a joint FAO/WHO ad hoc expert committee. FAO Nutrition Meetings Report Series No. 52. WHO Technical Report Series No. 522. ISBN 9241205229 Rome and Geneva. https://apps.who.int/iris/handle/10665/41042 (Accessed 11.03.2020).

FAO, WHO and UNU (United Nations University). 2001. Human energy requirements. Report of a Joint FAO/WHO/UNU Expert Consultation. Rome, 17-24 October 2001. ISBN 92-5105212-3 Rome, 2004. Chapters \# 1-9 and Annex 3. FAO FOOD AND NUTRITION TECHNICAL REPORT SERIES 1; ISBN 92-5-105212-3. Available from: http://www.fao.org/ 3/y5686e/y5686e00.htm\#Contents (Accessed 31.06.2019).

FAO, WFP and IFAD. 2012. "Economic Growth is Necessary But not Sufficient to Accelerate Reduction of Hunger and Malnutrition." The State of Food Insecurity in the World 2012. Available from: http://www.fao.org/docrep/016/ i3027e/i3027e.pdf (Accessed 31.06.2019).

FiBL and IFOAM. 2015. The World of Organic Agriculture Statistics and Emerging Trends 2015. Edited by Helga Willer and Julia Lernoud. Available from: https://shop.fibl.org/ chen/mwdownloads/download/link/id/686/ ISBN FiBL 9783-03736-271-6 - ISBN IFOAM 978-3-944372-12-9. (Accessed 30.04.2015).

Fogel RW. 2000. The fourth Great Awakening and the Future of Egalitarianism. ( Fogel, R.W. is the winner of 1993 Nobel Prize in Economics). The University of Chicago Press. Chicago and London, ISBN 0-226-25662-6.

Fogel RW, Costa DL. 1997. A theory of technophysio evolution, with some implications for forecasting population, health care costs, and pension costs. Demography 34: 49-66. Available from: https://pubmed.ncbi.nlm.nih.gov/9074831/ (Accessed 19.03. 2018).

Food and Nutrition Bulletin, vol. 33, no. 3 (supplement) (C) 2012, The United Nations University. Available from: https://www.ncbi.nlm.nih.gov/pubmed/23193766 (Accessed 18.11.2019).
Friedman M. 1952. "A Method of Comparing Incomes of Families Differing in Composition. Studies in Income and Wealth.” Available from: http://www.nber.org/chapters/ c9763.pdf Available also from: http://ssrn.com/ abstract $=1789646$ (Accessed 15.01.2015).

Frongillo EA. Jr. 1999. Validation of measures of food insecurity and hunger. J. Nutr., 1999 Feb;129(2S Suppl): 506S-509S. doi: 10.1093/jn/129.2.506S. Division of Nutritional Sciences, Cornell University, Ithaca, NY 14853-6301, USA. Available from: https://www.ncbi.nlm.nih.gov/pubmed/10064319 (Accessed 21.09.2019).

Hallström E, Börjesson P. 2013. Meat-consumption statistics: reliability and discrepancy. Sustainability: Science, Practice, \& Policy 9(2):37-47. Published online Jul 11, 2013. Available from: http://www.google.de/archives/vol9iss2/1203-008.hallstrom. html (Accessed 19.03.2019).

Hasimoglu S. 1989. Adult Human Unit versus Per Capita: A New Approach in Evaluating the Production, Consumption and Distribution of Food Commodities Through out the World. Salina, Kansas. (A forty-seven page paper, unpublished. Obtained, Copyright Registration Certificate-April 10, 1989, Kansas City, Missouri, USA.

Hasimoglu S. 1998. Per adult human unit versus per capita, a new approach in evaluating the production, consumption and distribution of food commodities throughout the world. ADSA-ASAS Joint Meeting, Denver, Colorado. J. of Animal Sci., 76 (1) 539.

Hasimoglu S. 1999. Per adult human unit (PAHU) versus per capita (PC) approach for evaluation of food commodities. Third International Food Data Conference July 4-7, 1999. UNFAO, Back to Basics, Page 74. Abstract: Rome/Italy.

Hasimoglu S. 2001. Future for red meat consumption can not be accurately evaluated by using per capita. A different approach: Per adult human unit versus per capita. International Animal Agriculture and Food Science Conference, FASS Annual Joint Meeting Abstracts, Journal of Animal Science, Vol. 79, Supplement 1, Abstract \# 271, p.65, July 24-28, 2001, Indianapolis, Indiana.

Hasimoglu S. 2012. Food (meat) consumption and socioeconomic context of EU on PC versus alternative approach PAHU. 2nd Organic Animal Husbandry Conference. Hamburg, Trenthorst, 12-14 September 2012, Special Issue Congress Book, pp. 43-46.

Hasimoglu S. 2014a. "Rethinking on Household/Population Anthropometric and Real Food Consumer Demand Evaluations of EU27/Candidates by Using Per Capita (PC) versus Per Adult Human Unit (PAHU) Method/1999-20102020." In IFOAM-Buğday 18th International World Congress Book, pp. 1089-1094. Istanbul, Turkey.

Hasimoglu S. 2014b. "Redefining Self Made Error Sources Per Capita $(\mathrm{PC})$; New PAHU Method $=\left(\mathrm{PC}^{\mathrm{gac}}=\right.$ Age and Gender Corrected Per Capita) on UNIT Basis. Panel Discussion Subject: How Does the Organic World of Globe and EU Need to Change Its Organic Food Consumption Evaluations for 2017-2020 and Which Targets to AimComparing Per Capita-PC versus Per Adult Human Unit Method-PAHU Evaluations." In IFOAM-Buğday 18th International World Congress Book, pp. 13-15, Istanbul.

Hasimoglu S, Aksakal V. 2015. Per Capita (PC) versus Per Adult Human Unit Method (PAHUM): A Net Assessment of EU28Population, Family/Household, Food Consumption and Environmental Impact. Journal of Environmental Science and Engineering, A 4 (2015) 273-281. doi: 10.17265/21625298/2015.07.002. http://www.davidpublisher.org/Public/ uploads/ Contribute/55f90ce89e1a9.pdf

Hasimoglu S. 2018. Innovated Par Adult Human Unit Method (PAHUM) versus Error Bound Per Capita (PC) Evaluations Rectifying the Unnoticed/Disregarded PC projections error for the Global Food Security. E-poster Presentation is prepared and sent for United Nations Decade of Action on Nutrition - 20162025. Accelerating the End of Hunger and Malnutrition Bangkok Conference, Nov. 28-30, 2018, Bangkok, Thailand. Global Conference Organized by IFPRI and FAO. 
Hasimoglu S. 2019. Disregarded and /or Ignored Reality: Inaccurate Hunger and Poverty Claims Based on Per Capita Metric Evaluations vs. Per Adult Human Unit Method or called Age and Gender Corrected Per Capita $\left(\mathrm{PC}^{\mathrm{agc}}\right)$. (Not published - shasimoglu@gmx.de), Schwerin, Germany.

Hasimoglu S. 2020. Impact of Innovated Per Adult Human Unit Method $(\mathrm{PAHUM})=\left(\right.$ Age and Gender Corrected $\left.\mathrm{PC}^{\mathrm{agc}}\right)$ versus Per Capita(PC) on Measuring the Capacity of Nigeria, Tanzania and Ethiopia to Produce Reliable, Timely, and Sustainable Agriculture Data (CEREAL) for Their Food Security. IFOAM Organic World Congress, 2020 in Rennes, France. Accepted OWC2020-SCI-1137, WWW,OWC.ifoam.bio/ 2020. (Postponed to Sept., 6-10, 2021). ORCID identifier is 00000002-9661-6381. shasimoglu@gmx.de

Hasimoglu S. 2021. Impact of Innovated Per Adult Human Unit Method (PAHUM) vs. Error Bound Per Capita (PC): Recalibration of EU and Developing Countries (India), Family/ Households' Population, Food Security and Environmental Sustainability is ACCEPTED for publication as a book chapter in the following book: Challenging Issues on Environment and Earth Science Vol. 5. (International Book). F. No. SD1/BP/2300F/5687 (Ref. no. 2021/BP/2300F) Book Publishing International, https://www.bookpi.org/. shasimoglu@gmx.de .

Jones AD, Ngure FM, Pelto G, Young SL. 2013. What are we assessing when we measure food security? A compendium and review of current metrics. Adv. Nutr. 2013. Sept; 4(5): 481-505. Available from: https://www.ncbi.nlm.nih.gov/ pubmed/24038241 (Accessed, 6 and 17. 11. 2019).

Karageorgou D, Imamura F, Zhang J, Shi P, Muzaffarian D, Micha R. 2019. Assessing dietary intakes from household budget surveys: A national analysis in Bangladesh. 2018 Aug 27;13(8):e0202831. doi: 10.1371/journal.pone.0202831. eCollection 2018. Available from: https://www.ncbi.nlm.nih.gov/ pubmed/30148863 (Accessed 20.11.2019).

Kelly A, Becker W, Helsing E. 1991. Food balance sheets. Food and health data: their use in nutrition policy-making. Copenhagen: WHO Regional Office for Europe; 1991. pp. 3947. Available from: https://agris.fao.org/agris-search/ search.do?recordID=XF19920070791 (Accessed 07.05.2020).

Khatibzadeh S, Kashaf MS, Micha R, Fahimi S, Shi P, Elmadfa I, Kalantarian S, Wirojratana P, Ezzati M, Powles J, Mozaffarian D. 2016. Behalf of the Global Burden of Diseases Nutrition, and Chronic Diseases Expert Group (NutriCode), Bull World Health Organ. 2016 Dec 1; 94(12): 931-934. Published online 2016 Sep 16. doi: 10.2471/ BLT.15.156323. Available from: https://www.ncbi.nlm.nih.gov/pmc/articles/PMC5153920/\#R1 0 (Accessed 07.05.2020).

Kleiber M. 1947. Body Size and Metabolic Rate. Physiol., Reviews. XXXII: 511-526.

Kleiber M. 1961. The Fire of Life, Introduction to Animal Energetic, John Wiley, NY.

Kumar P. 2019. GDP is no longer an accurate measure of economic progress. Here's why. World Economic Forum. Chief, Ecosystem Services Economics Unit. Available from: https://www.weforum.org/agenda/2018/11/forget-gdp-forthe-21st-century-we-need-a-modern-economic-measure/ ?fbclid=IwAR2yVDinHSfySe6C7UV2_pZlmt9wc2AA5efx hwThPMBCAjAVFD7vf9_gJpk (Accessed 29.07. 2019).

Lambert P, Yitzhaki S. 2000. "The Inconsistency between Measurement and Policy Instruments in Family Income Taxation.” Available from: http://ssrn.com/abstract=1789646 (Accessed 25.01.2015).

Naska A, Berg MA, Cuadrado C, Freisling H, Gedrich K, Gregoric M, Kelleher C, Leskova E, Nelson M, Pace L, Remaut AM, Rodrigues S, Sekula W, Sjöstrom M, Trygg K, Turrini A, Volatier JL, Zajkas G, Trichopoulou A. 2008. Data Food Networking (DAFNE) participants. Food balance sheet and household budget survey dietary data and mortality patterns in Europe. Br J Nutr. 2009 Jul;102(1):166-71. doi: 10.1017/S000711450809466X.
NRC. 1989. Recommended Dietary Allowances: (National Research Council). Washington (DC): ISBN-10: 0-30904633-5ISBN-10: 0-309-04041-8, 10th Edition. Available from: https://www.ncbi.nlm.nih.gov/books/NBK234938/ (Accessed 26.02.2020).

OECD and JRC-EU Commission. 2013. "Handbook on Constructing Composite Indicators." Methodology and User Guide. Available from: http://compositeindicators.jrc.ec.europa.eu/ and/or http://www.oecd.org/std/ clits/42495745.pdf (Accessed 15.03.2015.

Pingali P, Ricketts K. 2014. Mainstreaming Nutrition Metrics in Household Surveys - Toward a Multidisciplinary Convergence of Data Systems. Annals of the New York Academy of Sciences, 1331: 249-257. Available from: https://www.ncbi.nlm.nih.gov/pubmed/25407161 (Accessed 24.04.2019).

Pingali P. 2016. Opinion: The Hunger Metrics Mirage: There's Been Less Progress on Hunger Reduction Than it Appears. Proceedings of the National Academy of Sciences; 113 (18) 4880-4883. Available from: https://www.researchgate.net/ publication/301829239_Opinion_The_hunger_metrics_mira ge_There's_been_less_progress_on_hunger_reduction_than _it_appears (Accessed 24.04.2019).

Quora. 2020. Why do we need a standard unit of measurements? Available from:https://www.quora.com/Why-is-it-importantto-use-standardized-units-of-measurement (Accessed 08.02.2020).

Rosling H, Rosling O, Rosling A. 2018. Factfulness.Hodder and Stoughton Ltd., Carmelite House, 50 Victoria Embankment, London. ISBN 9784731473637467.

Tedford RJ, Capps O, Havlicek J. 1986. “Adult Equivalent Scales Once More: A Developmental Approach." American Agricultural Economics Association 68 (2): 322-333.

Thaller G. 2016. Big Ideas at Davos: How to feed the hungry? World Economic Forum. Available from: https://www.cbsnews.com/video/big-ideas-at-davos-how-tofeed-the-hungry/ (Accessed 16.09.2019.

Thoma M. 2016. Why GDP fails as a measure of well-being. Money Watch January 27, 2016, Available from: https://www.cbsnews.com/news/why-gdp-fails-as-ameasure-of-well-being/ (Accessed 15.11.2016).

Thomson S. 2016. GDP a poor measure of progress, say Davos economists. World Economic Forum. Available from: https://www.weforum.org/agenda/2016/01/gdp (Accessed 25.04.2017).

Tilman D, Blazer C, Hill J, Befort BL. 2011. Global food demand and the sustainable intensification of agriculture. Proceedings of the National Academy of Sciences, 108:20260-, 20264. Available from: https://www.pnas.org/content/108/50/ 20260.short (Accessed 20.02. 2020).

Torun B. 2001. Energy requirements of children and adolescents. Background paper prepared for the joint FAO/WHO/UNU Expert Consultation on Energy in Human Nutrition, 2001. Available from: http://www.fao.org/3/a-y5686e.pdf (Accessed 26.02.2020).

Trading Economics. 2016. Turkey - Cereal production (metric tons). Available from: https://tradingeconomics.com/ turkey/cereal-production-metric-tons-wb-data.html (Accessed 24.04.2019).

UNDESA. 2015. UN Department of Economic and Social Affair (UNDESA). 2015. The World Population Prospects: 2015 Revision. Available from: https://www.un.org/en/ development/desa/publications/world-population-prospects2015-revision.html (Accessed 28.04.2015).

UNFPA. 2012. Population Matters for Sustainable Development. UNFPA Technical Division, No. of pages: 32. Available from: https://www.unfpa.org/publications/population-matters sustainable-development (Accessed 10.05.2019).

Wadan, Lal, N. 2012. "Poverty Analysis in Vanuatu: A Critical Review and Alternative Formulation." Research Centre for the Pacific Islands. South Pacific Studies Vol.33, No.1, 2012. 
Weisell, R. and M.C. Dop. 2012. The adult male equivalent concept and its application to Household Consumption and Expenditures Surveys (HCES). Food and Nutrition Bulletin, vol. 33, no. 3 (supplement) (C) 2012, The United Nations University. Available from: https://journals.sagepub.com/ doi/pdf/10.1177/15648265120333s203 14.09.2020).
WHO. 1985. Energy and protein requirements: Report of a joint FAO/WHO/UNU expert consultation. WHO Technical Report Series No. 724. Geneva, Switzerland.

World Economic Forum. 2016. GDP a poor measure of progress, say Davos economists. World Economic Forum- by Stephanie Thompson. Available from: https://www.weforum.org/ agenda/2016/01/gdp (Accessed 29.11.2019). 